\title{
Technology and telecommunications: a panacea in the COVID-19 crisis
}

\author{
Muhammad Khurram Khan ${ }^{1}$
}

Accepted: 11 January 2022 / Published online: 24 January 2022

() The Author(s), under exclusive licence to Springer Science+Business Media, LLC, part of Springer Nature 2022

The COVID-19 pandemic has highlighted the crucial role of the technology and telecommunication sectors in keeping businesses, governments, and communities connected and working. As a result of the pandemic's socio-economic devastation, people all across the world are relying on technology for knowledge, social communication, and work from home. The use of the Internet, cloud-based applications, and online communication tools has been spurred exponentially since the pandemic emerged in 2019. The telecom sector, in particular, has proven to be essential for businesses and individuals during this unprecedented time, and it has helped society thrive.

The world has witnessed the benefits of connectivity in this hard time, which has not only kept us connected but has also opened new horizons for innovation and sustainability. It is anticipated that the demand for the internet and telecommunications networks will increase even after the pandemic is over. However, as per United Nations data, 37\% of the world's population, or 3 billion people, have never used the Internet-and most of them live in developing countries. Therefore, this profound digital divide is one of the most striking and surprising inequalities highlighted by COVID19. It is indeed a great challenge for global leaders to keep all parts of the world connected and decrease the digital divide.

Access to the Internet is no longer a luxury; it has become a prerequisite for human survival and essential to well-being. Therefore, the role of telecom operators and service providers is imperative in offering cheaper and more reliable connectivity that can be easily afforded by all segments of society. Perhaps, this could be taken as a social and moral responsibility to benefit the underrepresented and underdeveloped nations during this crisis. Fortunately, this act has been demonstrated by many digital platforms and online meeting tools by offering their time-limited free services to the masses. This has helped a lot of those who are unable to avail

Muhammad Khurram Khan

mkhurram@KSU.EDU.SA

1 King Saud University, Riyadh, Saudi Arabia of paid and subscription-based services. Hence, it remains a win-win situation for the service providers and the users.

In response to the pandemic, the excessive use of the telecom and tech sectors is helping to accelerate digital transformation across the globe. The importance of data, cloud computing, cybersecurity, blockchain, IoT, AI, automation, and many other emerging technologies has never been felt before as it is now. The telecommunications sector, as the lifeblood of modern communications, would continue to play an instrumental role in keeping the world connected and thriving for all vertical technologies and industries. It is hoped that the post-COVID-19 world will be more digitally connected with more opportunities and prospects in all walks of life.

While recent times are certainly unprecedented and have caused turmoil, our editorial board members and reviewers deserve sincere gratitude and appreciation. They have been very active in performing their editorial and review tasks. Additionally, we cannot neglect to recognize and thank departing editorial board members who have dedicated their valuable time and effort to serving the journal during their tenure. Furthermore, some new associate editors have also joined us, who have demonstrated a great passion to continue their services with the same enthusiasm as their predecessors. The induction of new associate editors to the editorial board should help improve the quality of content published by the journal in a timely manner.

We are also deeply grateful to the editorial staff for providing extraordinary services to the contributing authors, reviewers, and editors. Furthermore, we would like to express our appreciation to Ms. Kanishkaa Sridhar for her dedication to the journal and smooth editorial process. Radika Devakumar, who has always worked tirelessly to publish the journal's contents on time, deserves a huge round of thanks. To assist in keeping our journal's website up-to-date, Ms. Ash Highfill has recently joined us as an editorial assistant. Mr. Matthew Amboy, a senior editor at Springer-Nature, is a valuable resource in our efforts to improve the journal's quality. 
As we approach the new year, let's hope that the COVID19 pandemic and its challenges can be overcome so that life can return to normal. We wish our readers, authors, reviewers, editorial staff, and editorial board members a happy, healthy, and productive new year!
Muhammad Khurram Khan, Ph.D.

Editor-in-Chief.

Telecommunication Systems (Springer-Nature).

King Saud University, Saudi Arabia.

Twitter: @khurramcyber.

Web: http://www.professorkhurram.com

Publisher's Note Springer Nature remains neutral with regard to jurisdictional claims in published maps and institutional affiliations. 